\title{
SYNDROMES RELATED TO SODIUM AND ARGININE VASOPRESSIN ALTERATIONS IN POST-OPERATIVE NEUROSURGERY
}

\author{
Ana P.D. Cardoso', Desanka Dragosavac, Sebastião Araújo, Antonio L.E. Falcão', \\ Renato G.G. Terzi ${ }^{1}$, Margaret de Castro ${ }^{2}$, Fabiana G. Marcondes ${ }^{1}$, Taís G. Melo ${ }^{1}$, \\ Rosmari A.R.A. Oliveira ${ }^{1}$, Eliana A. Cintra ${ }^{1}$
}

\begin{abstract}
Background: Cerebral salt wasting syndrome (CSWS), syndrome of inappropriate antidiuretic hormone secretion (SIADH) and diabetes insipidus (DI) are frequently found in postoperative neurosurgery. Purpose: To identify these syndromes following neurosurgery. Method: The study included 30 patients who had been submitted to tumor resection and cerebral aneurysm clipping. Sodium levels in serum and urine and urine volume were measured daily up to the $5^{\text {th }}$ day following surgery. Plasma arginine vasopressin (AVP) was measured on the first, third and fifth days post-surgery. Results: CSWS was found in $27 / 30$ patients $(90 \%)$, in $14(46.7 \%)$ of whom it was associated with a reduction in the levels of plasma AVP (mix syndrome). SIADH was found in $3 / 30$ patients $(10 \%)$. There was no difference between the two groups of patients. Conclusion: CSWS was the most common syndrome found, and in half the cases it was associated with DI. SIADH was the least frequent syndrome found.
\end{abstract}

KEY WORDS: cerebral salt wasting syndrome, syndrome of inappropriate antidiuretic hormone secretion, diabetes insipidus, mixed syndrome, neurosurgery.

\begin{abstract}
Síndromes relacionadas com alterações de sódio e arginina-vasopressina no pós-operatório de neurocirurgia

RESUMO - Introdução: A síndrome perdedora de sal (SPS), síndrome da secreção inapropriada do hormônio antidiurético (SIADH) e diabetes insipidus (DI) são freqüentemente encontradas no pós-operatório de neurocirurgia. Objetivo: Identificar essas síndromes relacionadas à neurocirurgia. Método: Foram estudados 30 pacientes submetidos à ressecção de tumor $(n=19)$ e clipagem de aneurisma $(n=11)$ cerebral durante os primeiros cinco dias do pós-operatório. Os pacientes foram submetidos a dosagens diárias de sódio sérico e urinário até o $5^{\circ}$ dia pós-operatório, com controle de volume urinário neste período e dosagem de arginina-vasopressina (AVP) plasmática no $1^{\circ}, 3^{\circ}$ e $5^{\circ}$ dias pós-operatórios. Resultados: A SPS foi encontrada em $27 / 30$ pacientes $(90 \%)$, em 14/27 (46,7\%) associada à diminuição dos níveis de AVP plasmática (síndrome mista). A SIADH foi encontrada em 3/30 pacientes (10\%). Não houve diferença entre os dois grupos de pacientes. Conclusão: A SPS foi a síndrome mais freqüente, em metade de casos associada ao DI. A SIADH foi a menos freqüente.
\end{abstract}

PALAVRAS-CHAVE: síndrome perdedora de sal, síndrome de secreção inapropriada de hormônio antidiurético, diabetes insipidus, síndrome mista, neurocirurgia.

Alterations in sodium are frequently found in neurological and neurosurgical patients ${ }^{1-7}$ and are associated with alterations in the osmolarity of the extracellular medium and changes in the volume of the cells of the central nervous system (CNS). They may aggravate the condition of these patients ${ }^{8}$. Hyponatremia is the sodium disturbance most frequently found in patients with severe cerebral dam- age occurring in $29-33 \%$ of patients following subarachnoid hemorrhage $(\mathrm{SAH})^{9-12}$. Initially, hyponatremia in patients with intracranial disease was attributed to cerebral salt wasting syndrome (CSWS), as proposed by Peters et al. in $1950^{13}$. Later, the syndrome of inappropriate antidiuretic hormone secretion (SIADH), described by Schwartz et al. in $1957^{14}$, became accepted as the principal cause of hypona-

${ }^{1}$ Intensive Care Unit, Department of Surgery, School of Medical Sciences, State University of Campinas, Campinas SP, Brazil (UNICAMP); ${ }^{2}$ Department of Clinical Pathology, Faculty of Medicine of Ribeirão Preto, University of São Paulo, Ribeirão Preto SP, Brazil (FMRP/USP). Financial support: Foundation for Research Support of the State of São Paulo (FAPESP), grant number 00/05990-9.

Received 30 January 2007, received in final form 18 May 2007. Accepted 25 June 2007. 
tremia in neurological patients with excessive urinary sodium loss, and the original concept of CSWS was abandoned ${ }^{1,8,14-17}$. Hypernatremia is the sodium disturbance least frequently found in these patients and its principal cause is neurogenic diabetes insipidus. Improved knowledge with respect to the physiology of arginine vasopressin (AVP), the possibility of its measuring by radioimmunoassay ${ }^{2,16-21}$ and the report of hypovolemia in the majority of neurological patients presenting hyponatremia and natriuresis, led investigators to question SIADH in brain disease. Many questions remain unanswered with respect to SIADH since few studies in which AVP was measured have been reported and results have been contradictory ${ }^{1,2,7}$. At the present time, CSWS has again been proposed as a cause of hyponatremia associated with neurological disease. The majority of patients diagnosed with SIADH are hypovolemic and, when treated with fluid restriction, may develop a stroke with consequent worsening of their neurological condition ${ }^{18}$, suggesting that CSWS may be the most probable cause of hyponatremia in these patients ${ }^{1,2,4,5,7,16,19}$. Other studies suggest that hyponatremia may be iatrogenic, secondary to the excessive administration of hypotonic liquids ${ }^{20}$.

CSWS and SIADH show very similar laboratory characteristics ${ }^{13-15}$ and are equally associated with neurological disease. However, they differ with respect to volemic states since SIADH is associated with normovolemia or hypervolemia, whereas CSWS is associated with fluid depletion ${ }^{2,4,5,7}$. Although SIADH is characterized by fluid retention, the majority of

Table 1. Demographic data, pre- and postoperative Glasgow Coma Scale score and neurologic diagnoses in patients of Group A and B.

\begin{tabular}{|c|c|c|c|c|c|c|}
\hline Patient & $\begin{array}{c}\text { Age } \\
\text { (years) }\end{array}$ & Sex & Race & $\begin{array}{c}\text { Pre-Op } \\
\text { GCS }\end{array}$ & $\begin{array}{c}\text { Post-Op } \\
\text { GCS }\end{array}$ & Diagnosis \\
\hline A1 & 62 & $\mathrm{M}$ & W & 15 & 15 & Tumor of the posterior fossa \\
\hline A2 & 37 & M & W & 15 & 15 & Frontal tumor \\
\hline A3 & 25 & $\mathrm{~F}$ & W & 15 & 15 & Orbital tumor \\
\hline A4 & 47 & $\mathrm{~F}$ & M & 15 & 14 & Left sphenoidal meningoma \\
\hline A5 & 17 & $\mathrm{~F}$ & w & 15 & 15 & Left temporal tumor \\
\hline A6 & 16 & M & W & 12 & 15 & Cerebellar tumor \\
\hline A7 & 26 & $\mathrm{~F}$ & W & 15 & Death & Intraventricular tumor \\
\hline A8 & 39 & $\mathrm{~F}$ & w & 15 & 15 & Meningoma \\
\hline A9 & 46 & M & W & 15 & 15 & Left frontal-parietal tumor \\
\hline A10 & 68 & $\mathrm{~F}$ & M & 15 & 15 & Central frontal meningoma \\
\hline A11 & 65 & $\mathrm{M}$ & w & Sedated & Death & Right frontal meningoma \\
\hline A12 & 60 & $\mathrm{~F}$ & w & 14 & 15 & Right frontal tumor \\
\hline A13 & 48 & M & w & 15 & 15 & Middle fossa tumor \\
\hline A14 & 59 & $\mathrm{~F}$ & W & 15 & Death & Left multiforme glioblastoma \\
\hline A15 & 68 & M & w & 15 & 15 & Cerebellar tumor \\
\hline A16 & 45 & $\mathrm{~F}$ & w & 14 & 15 & Left temporal meningoma \\
\hline A17 & 77 & M & W & 15 & 15 & Right parietal tumor \\
\hline A18 & 51 & $\mathrm{~F}$ & $\mathrm{~N}$ & 15 & 15 & Left posterior fossa meningoma \\
\hline A19 & 19 & M & w & 15 & 15 & Glomus jugular tumor \\
\hline B1 & 16 & $\mathrm{~F}$ & $\mathrm{~N}$ & 15 & 15 & Malformation left frontal stroke \\
\hline B2 & 45 & $\mathrm{~F}$ & W & 11 & 11 & Anterior communicating artery aneurysm \\
\hline B3 & 48 & $\mathrm{~F}$ & M & 15 & 15 & Anterior communicating artery aneurysm \\
\hline B4 & 46 & M & M & 10 & Death & Anterior communicating artery aneurysm \\
\hline B5 & 70 & $\mathrm{~F}$ & W & 15 & 15 & Anterior communicating artery aneurysm \\
\hline B6 & 78 & $\mathrm{~F}$ & W & 14 & 15 & Posterior communicating artery aneurysm \\
\hline B7 & 46 & M & W & 15 & Ischemic stroke & Anterior communicating artery aneurysm \\
\hline B8 & 39 & M & w & 15 & 15 & Aneurysm at the top of the basilar artery \\
\hline B9 & 36 & $\mathrm{~F}$ & w & 15 & 15 & Right middle cerebral artery aneurysm \\
\hline B10 & 30 & $\mathrm{~F}$ & W & 15 & 15 & Left middle cerebral artery aneurysm \\
\hline B11 & 15 & $\mathrm{M}$ & W & 15 & 15 & Anterior communicating artery aneurysm \\
\hline
\end{tabular}

$M$, male; F, female; op, operatory; W, white; $M$, mulatto; $N$, negro. 
Table 2. Alterations used in the differential diagnosis of syndromes responsible for sodium disturbances found in the postoperative phase of patients in this study.

\begin{tabular}{lccc}
\hline & CSWS & SIADH & DI \\
\hline Fluid balance & $\downarrow$ & Normal or $\uparrow$ & $\downarrow$ \\
Volume of urine & $\uparrow$ & Normal or $\downarrow$ & $\uparrow$ \\
Serum sodium & $\downarrow$ & $\downarrow$ & $\uparrow$ \\
Urinary sodium & $\uparrow$ & $\uparrow$ & Normal \\
Plasma AVP & Normal & $\uparrow$ & $\downarrow$ \\
\hline
\end{tabular}

$\downarrow$ decrease; $\uparrow$ increase.

patients show no signs of hypervolemia since onethird of the remaining fluid is maintained in the extracellular compartment, making diagnosis difficult ${ }^{8}$. Measurement of AVP can be useful in the differential diagnosis of these syndromes ${ }^{2,7}$. However, it can also be influenced by several factors involved in the postoperative phase of neurosurgical patients, that are able to stimulate the non-osmotic secretion of AVP, such as stress, an increase in intracranial pressure (ICP), pain, use of medication (antipsychotics, tricyclic antidepressives, carbamazepine, morphine, anesthetics, metoclopramide), hypovolemia, prolonged recumbency and positive-pressure mechanical ventilation $^{4,7,16,22-27}$. Considering that patients submitted to neurosurgery may frequently suffer sodium and AVP alterations of various causes and since differential diagnosis of these alterations is essential to guarantee adequate treatment, their accurate diagnosis is of great importance ${ }^{17,18}$.

The objective of the present study is therefore to identify the presence of syndromes related to sodium alterations occurring in neurological patients during the postoperative period.

\section{METHOD}

The study was carried out at the Teaching Hospital of the State University of Campinas (UNICAMP), Brazil. It was approved by the Internal Review Board under protocol number 142/99. Signed, informed consent was obtained from the patients themselves or from their next-of-kin prior to admission to the study.

Thirty consecutive patients (males and females) over 13 years of age, who had been submitted to craniotomy either for resection of a brain tumor (Group $A, n=19$ ) or for clipping of an aneurysm of the cerebral artery (Group $B, n=11$ ) were enrolled to the study. The groups of patients were considered homogenic with respect to the parameters of age, sex, race, and the pre- and postoperative Glasgow Coma Scale (GCS) scores, (Table 1). Sodium measurements in serum and urine (12 hour, overnight urine) were carried out on postoperative days 1-5 (D1-D5), urinary volume was measured in the 12-hour overnight period and plasma arginine vasopres$\sin (A V P)$ measurements were carried out by radioimmunoassay on postoperative days 1, 3 and 5 (D1, D3, D5).
Table 3. Plasma arginine vasopressin values on the $1^{\text {st }}, 2^{\text {nd }}$ and $3^{\text {rd }}$ postoperative days in patients of Groups $A$ and $B$

\begin{tabular}{|c|c|c|c|}
\hline Patient & D1 & D3 & D5 \\
\hline $\mathrm{A} 1$ & 27,5 & 1,1 & 2,0 \\
\hline $\mathrm{A} 2$ & 0.9 & 0.5 & 0.7 \\
\hline A3 & 0.7 & 0.5 & 0.4 \\
\hline A4 & 2.4 & 0.4 & 0.4 \\
\hline A5 & $<0.15$ & 0,7 & NM \\
\hline A6 & $<0.15$ & $<0.15$ & 0.6 \\
\hline A7 & 0.7 & 1.2 & Dead \\
\hline A8 & 0.9 & 0.5 & $<0.15$ \\
\hline A9 & 1.3 & 1.0 & NM \\
\hline A10 & 2.6 & 1.9 & 2.2 \\
\hline A11 & 1.3 & 0.8 & 0.7 \\
\hline A12 & 0.6 & 1.1 & NM \\
\hline A13 & 0.4 & $<0.15$ & 0.8 \\
\hline A14 & 0.7 & 0.5 & 0.7 \\
\hline A15 & 0.3 & 1.0 & 0.5 \\
\hline A16 & 0.4 & 0.2 & 0.3 \\
\hline A17 & 0.15 & $<0.15$ & NM \\
\hline A18 & 0.75 & 1.4 & NM \\
\hline A19 & 1.7 & 1.3 & 1.4 \\
\hline B1 & 0.9 & 0.9 & 0.7 \\
\hline B2 & 1.2 & 1.2 & 0.9 \\
\hline B3 & 2.4 & 0.4 & 0.6 \\
\hline B4 & 1.3 & 8.2 & Dead \\
\hline B5 & 0.6 & $<0.15$ & 0.7 \\
\hline B6 & 8.5 & 2.0 & 0.5 \\
\hline B7 & 0.8 & 0.3 & 0.5 \\
\hline B8 & 0.8 & 0.6 & 0.15 \\
\hline B9 & 0.4 & 0.6 & 0.6 \\
\hline B10 & 2.5 & 1.8 & NM \\
\hline B11 & 1.7 & 1.2 & NM \\
\hline
\end{tabular}

Normal value of plasma AVP: 0.5-5.0 pg/mL; NM, not measurable.

Patients received a minimum volume of $30 \mathrm{~mL} / \mathrm{kg}$ of $0.9 \% \mathrm{Na} C \mathrm{Cl}$ per day during the postoperative period. Central venous blood pressure was maintened above $10 \mathrm{mmHg}$. 
Table 4. Alterations in sodium, natriuresis, urinary volume and plasma AVP found in patients of both groups with the respective diagnoses of the syndromes involved.

\begin{tabular}{|c|c|c|c|c|c|c|c|}
\hline Patient & Hyponatremia & Hypernatremia & Natriuresis & Polyuria & $\uparrow \mathrm{AVP}$ & $\downarrow$ AVP & Diagnosis \\
\hline A1 & $x$ & & $x$ & $x$ & & $x$ & SIADH \\
\hline A2 & & & $\mathrm{x}$ & $\mathrm{x}$ & & & CSWS \\
\hline A3 & & & $x$ & $x$ & $x$ & & CSWS + DI \\
\hline A4 & $x$ & & $x$ & $\mathrm{x}$ & $x$ & & CSWS + DI \\
\hline A5 & & & $x$ & $x$ & $x$ & & CSWS + DI \\
\hline A6 & $x$ & & $\mathrm{x}$ & $\mathrm{x}$ & $\mathrm{x}$ & & CSWS + DI \\
\hline A7 & & $\mathrm{x}$ & $\mathrm{x}$ & $\mathrm{x}$ & & & CSWS \\
\hline A8 & $\mathrm{x}$ & & $\mathrm{x}$ & $x$ & $\mathrm{x}$ & & CSWS + DI \\
\hline A9 & $x$ & & $x$ & $x$ & & & csws \\
\hline A10 & $x$ & & $\mathrm{x}$ & $x$ & & & CSWS \\
\hline A11 & $x$ & & $x$ & $x$ & & & csws \\
\hline A12 & & & $\mathrm{x}$ & $\mathrm{x}$ & & & CSWS \\
\hline A13 & $x$ & & $x$ & $x$ & $x$ & & CSWS + DI \\
\hline A14 & $\mathrm{x}$ & $\mathrm{x}$ & $\mathrm{x}$ & $\mathrm{x}$ & & & CSWS \\
\hline A15 & $\mathrm{x}$ & & $\mathrm{x}$ & $\mathrm{x}$ & $\mathrm{x}$ & & CSWS + DI \\
\hline A16 & $\mathrm{x}$ & & $\mathrm{x}$ & $\mathrm{x}$ & $\mathrm{x}$ & & CSWS + DI \\
\hline A17 & & & $\mathrm{x}$ & $\mathrm{x}$ & $x$ & & CSWS + DI \\
\hline A18 & $x$ & & $x$ & $x$ & & & csws \\
\hline A19 & & & $\mathrm{x}$ & $\mathrm{x}$ & & & CSWS \\
\hline B1 & & & $\mathrm{x}$ & $\mathrm{x}$ & & & CSWS \\
\hline B2 & $x$ & & $x$ & $x$ & & & csws \\
\hline B3 & & & $x$ & $x$ & $x$ & & CSWS + DI \\
\hline B4 & $x$ & & & $x$ & & $x$ & SIADH \\
\hline B5 & $\mathrm{x}$ & & $\mathrm{x}$ & $\mathrm{x}$ & $\mathrm{x}$ & & CSWS + DI \\
\hline B6 & $x$ & & & $\mathrm{x}$ & & $\mathrm{x}$ & SIADH \\
\hline B7 & & & $x$ & $x$ & $x$ & & CSWS + DI \\
\hline B8 & $x$ & & $x$ & $x$ & $x$ & & CSWS + DI \\
\hline B9 & & & $\mathrm{x}$ & $\mathrm{x}$ & $\mathrm{x}$ & & CSWS + DI \\
\hline B10 & $x$ & & $\mathrm{x}$ & $\mathrm{x}$ & & & CSWS \\
\hline B11 & $x$ & & $\mathrm{x}$ & $\mathrm{x}$ & & & CSWS \\
\hline
\end{tabular}

Hyponatremia=serum sodium $<135 \mathrm{mEq} / \mathrm{L}$; hypernatremia=serum sodium $>145 \mathrm{mEq} / \mathrm{L}$; Natriuresis=urinary sodium $>110 \mathrm{mEq} / 12 \mathrm{~h}$; polyuria=urinary volume $>1050 \mathrm{~mL} / 12 \mathrm{~h}$; normal AVP=0.5-5.0 pg/mL; X-present; $\downarrow$ decrease; $\uparrow$ increase.

Exclusion criteria included: age $<13$ years, pregnan$c y$, diagnosis of hypophyseal tumor and previously diagnosed alterations in cardiac, renal, adrenal, thyroid or hepatic function.

Diagnostic criteria used for related syndromes are shown in Table 2.

The Mann-Whitney test was used in the statistical analysis of the comparison of continuous measurements between the two groups and the Chi-square test or Fisher's Exact test were used for the comparison of proportions. Significance was established at $5 \%$.

\section{RESULTS}

Hydro-electrolytic and plasma AVP alterations - Plasma AVP levels are shown in Table 3. Table 4 shows the occurrence of alterations in sodium, urinary volume and plasma AVP for each patient. These alterations, permitted a differential diagnosis of the syndromes (CSWS, SIADH, DI), based on the diagnostic criteria already described in Table 2.

Distribution of syndromes according to group - There were no statistically significant differences in the distribution of syndromes between the two groups $(p=0.7737)$, as shown in Table 5 . This allowed us to group them into one single set, showing that of the 30 patients in the study, 27 developed CSWS, of which 13/27 developed CSWS alone and 14/27 developed CSWS associated with DI (mixed syndrome); in 
Table 5. Distribution of syndromes between the groups.

\begin{tabular}{lcccc}
\hline & CSWS & CSWS + DI & DI & SIADH \\
\hline Group A & 9 & 9 & 0 & 1 \\
Group B & 4 & 5 & 0 & 2 \\
Total & 13 & 14 & 0 & 3 \\
$\%$ & 43.3 & 46.7 & 0 & 10 \\
\hline Fisher's exact test $(\mathrm{p}=0.7737)$ & & & &
\end{tabular}

Fisher's exact test $(p=0.7737)$.

this period no patient developed DI on its own and three presented SIADH.

\section{DISCUSSION}

Hyponatremia in neurological and neurosurgical patients can occur secondary to cerebral salt wasting syndrome ${ }^{10,13,18,28}$ or syndrome of inappropriate antidiuretic hormone secretion ${ }^{15}$ and iatrogenically as a result of a large infusion of hypotonic liquid ${ }^{20}$. In this study, no patient received hypotonic liquid in excess, and sodium and fluid replacement were carried out whenever necessary. Therefore, hyponatremia, present in $19 / 30$ patients $(63.3 \%)$ in the postoperative phase, must not have occurred iatrogenically but must have been secondary to CSWS or SIADH.

The most common cause of hypernatremia in neurological patients is diabetes insipidus and this condition may also occur iatrogenically or secondary to neurological lesions. The most common form of diabetes insipidus is that wich folows trauma or surgery to the region of the pituitary and hypothalamus ${ }^{29}$. As we excluded patients with pituitary tumor there were no patients with isolated diabetes insipidus. Diabetes insipidus may exibit as three patterns: transient, permanent and triphasic. The triphasic patern is observed more often clinicaly. First, a polyuric phase occurs and lasts 4-5 days.

Inhibition of ADH causes the polyuric phase. Second, an antidiuretic phase of 5-6 days occurs, with results from release of stored hormone and the third phase can be permanent $\mathrm{DI}$, when stores of $\mathrm{ADH}$ are exausted and the cells that produce more $A D H$ are absent or unable to produce.

In this study, hypernatremia was observed iatrogenically in $2 / 30$ patients $(6.7 \%)$ due to the administration of hypertonic liquid and because of the excess correction of hyponatremia. No patient presented hypernatremia associated with low levels of AVP.

Urine sodium loss (natriuresis) can be caused by CSWS or SIADH and most studies show that its most probable cause is CSWS, natriuresis being preceded by hyponatremia and not correlated to AVP. This sug- gests that CSWS is the principal cause of natriuresis in these patients ${ }^{2,10,30}$. The present study also shows that most of the patients who developed hyponatremia and natriuresis presented no increase in plasma AVP levels, suggesting that the probable cause of natriuresis in these patients is CSWS.

Increased plasma levels of AVP occur due to SIADH. However, most studies show that in the immediate postoperative period and in the initial stages of $\mathrm{SAH}$, the increase in AVP may be attributed to surgical stress, increased ICP, use of medication (metochlopramide, morphine, anticonvulsants), pain and/or loss of blood during surgery, and not to SIADH $2,10,20,27,28$. Some authors also suggest the participation of AVP in CSWS. This hypothesis suggests that hypovolemia stimulates AVP secretion in a physiologically correct manner despite the suppressive effect of hyponatremia on AVP, and that in SIADH the increase in AVP occurs inappropriately since there is an expansion in the actual vascular volume.

In this study, increased plasma AVP measurements $(>5.0 \mathrm{pg} / \mathrm{mL}$ ) were found in only $3 / 30$ patients $(10 \%)$, and $3 / 150$ measurements at the first posoperatory day. Considering that none of these patients developed hypovolemia, which could have justified the increase in AVP, the cause may be due to SIADH or to the physiological response to surgical stress.

Decreased plasma levels of AVP $(<0.5 \mathrm{pg} / \mathrm{mL})$ were found in $14 / 30$ patients $(46.7 \%)$, in 23 of 150 measurements during the postoperative period. The most common cause of the reduction in plasma secretion of AVP in neurological patients is hyponatremia or secondary to neurological lesions .

In this study, the reduction in the plasma levels of AVP was associated with hyponatremia. However, all patients also presented CSWS concomitantly and reduction in the plasma levels of AVP thereby prevent the patients from developing higher hyponatremia. It was also observed that, in the postoperative phase, $27 / 30$ patients $(90 \%)$ developed cerebral salt wasting syndrome, 13 of these (43.3\%) developing CSWS alone and 14/27 (46.7\%) developing CSWS associated 
with diabetes insipidus (mixed syndrome). Three out of thirty patients (10\%) suffered an increase in plasma AVP levels. There was no statistically significant difference in the distribution of syndromes between the two groups ( $p=0.7737)$, which allows us to analyze them as a single set.

The incidence of CSWS among all the patients was greater than that of SIADH, which is in agreement with reports from various other authors, who also observed a greater prevalence of CSWS, compared to SIADH in neurological patients $s^{1,2,4,5,10,18,30}$. The coexistence of DI and CSWS (mixed syndrome) observed in our patients has also been described by Yamaki et al. ${ }^{17}$, who studied two patients postoperatively following surgery for pituitary tumor and observed the presence of severe natriuresis and hyponatremia in a study patient who developed DI (fluid loss $>2.36 \mathrm{~mL} / \mathrm{kg} / \mathrm{h}$ ), which led the authors to conclude that hyponatremia resulting from CSWS in intracranial diseases may develop in patients with DI. Similar findings were described by Laredo et al. ${ }^{29}$, who reported hypernatremia resulting from $\mathrm{DI}$, followed by hyponatremia due to sodium urinary loss compatible with CSWS, in the immediate postoperative period of two neurosurgical patients. However, plasma measurements of AVP were not carried out in either of these studies.

Studies reported in the literature about the alterations in hydro-electrolytic control and the syndromes responsible for these disturbances are mostly case reports and retrospective studies. These studies include small, diverse populations and analyze few variables using a variety of methods. Few studies have been carried out using a control group and their results are conflicting. In these studies, the differential diagnosis between CSWS and SIADH is based on volemic state, as measured by indirect, insufficient methods with no comparative studies between the different methods. Also, in the majority of studies on CSWS in a group of patients, examples are cited but there are no group values.

In the present study, difficulty was found in controlling the water and sodium balance in patients spontaneously ingesting liquids. Otherwise, additional data could have been available, particularly in the case of those patients who developed CSWS associated with DI, justifying the association of these syndromes. Since the patients with CSWS are hypovolemic and volemic state is the most potent stimulus of AVP secretion, levels of the latter should be high. However, in this study, osmotic stimulus apparently prevailed over volemic state, leading to a fall in AVP in patients with CSWS. The doubt remains regarding whether the decrease in AVP associated with CSWS can be considered a compensatory mechanism or a "protector" of plasma sodium, increasing the loss of free water. This compensatory mechanism may increase fluid loss even further, which could be harmful to these patients. This fluid loss may indeed be compensatory and "protective" in the attempt to reduce the cerebral edema and intracranial hypertension that may be caused by the severe hyponatremia. In this case, a cerebral natriuretic factor may be involved in the physiopathology of CSWS, as suggested by some authors ${ }^{7,29,30}$.

There are no large studies reported in the literature on CSWS alone or in association with DI (mixed syndrome); neither are there studies on the participation of intracranial pressure (ICP) in the hydro-electrolytic imbalance of the syndromes involved. Unfortunately, in our study, ICP was also not routinely monitored. Therefore, additional studies are required to provide more data on the association of cerebral salt wasting syndrome with diabetes insipidus, the influence of intracranial pressure in hydro-electrolytic control, on the role of the atrial natriuretic factor and the possible existence of a brain natriuretic factor, involved in the pathophysiology of cerebral salt wasting syndrome.

In conclusion, in this study cerebral salt wasting syndrome was the syndrome most frequently found, being detected in $90 \%$ of cases, and was associated most often with diabetes insipidus (46.7\%) (mixed syndrome). Diabetes insipidus was not found alone in any of our patients. Syndrome of inappropriate antidiuretic hormone secretion was found less frequently (10\%) and may be merely a response to surgical stress. There was no difference between the two groups studied (cerebral tumor resection and clipping of cerebral artery aneurysm) in the incidence of the three syndromes. An adequate diagnosis is very important in defining treatment, reducing the complications and mortality related to the inadequate management of sodium disturbances during the neurological postoperative phase.

Acknowledgments - The authors would like to acknowledge the collaboration of the entire medical and nursing staff, as well as the physiotherapy staff of the ICU and the staff of the Department of Neurosurgery of the Teaching Hospital of UNICAMP. We would also like to thank the statistics group at the School of Medical Sciences, who contributed towards carrying out this study. Our thanks also go to the biologist, Laurione Cândido, of the Department of Clinical Pathology for her help in measuring vasopressin. 


\section{REFERENCES}

1. Nelson PB, Seif SM, Maroon JC, Robinson AG. Hyponatremia in intracranial disease: perhaps not the syndrome of inappropriate secretion of antidiuretic hormone (SIADH). J Neurosurg 1981;55:938-941.

2. Nelson PB, Seif S, Gutai J, Robinson AG. Hyponatremia and natriuresis following subarachnoid hemorrhage in a monkey model. J Neurosurg 1984; 60:233-237.

3. Diringer M, Landenson PW, Borel C, Hart GK, Kirsch JR, Hanley DF. Sodium and water regulation in a patient with cerebral salt wasting. Arch Neurol 1989;46:928-930.

4. Sivakumar V, Rajshekhar V, Chandy MJ. Management of neurosurgical patients with hyponatremia and natriuresis. Neurosurgery 1994;34:269274.

5. Damaraju SC, Rajshekhar V, Chandy MJ. Validation study of a central venous pressure-based protocol for the management of neurosurgical patients with hyponatremia and natriuresis. Neurosurgery 1997;40:312317.

6. Bacic A, Gluncic I, Gluncic V. Disturbances in plasma sodium in patients with war head injuries. Mil Medicine 1999;164:214-217.

7. Harrigan MR. Cerebral salt wasting syndrome. Crit Care Clin 2001;17: 125-138.

8. Palmer BF. Hyponatraemia in a neurosurgical patient: syndrome of inappropriate antidiuretic hormone secretion versus cerebral salt wasting. Nephrol Dial Transplant 2000;15:262-268.

9. Wong MF, Chin NM, Lew TW. Diabetes insipidus in neurosurgical patients. Ann Acad Med Singapore 1998; 27:340-343.

10. Wijdicks EF, Vermeulen M, Haaf JA, Hijdra A, Bakker WH, van Gijn J. Volume depletion and natriuresis in patients with a ruptured intracranial aneurysm. Ann Neurol 1985;18:211-216.

11. Hasan D, Wijdicks EF, Vermeulen M. Hyponatremia is associated with cerebral ischemia in patients with aneurysmal subarachnoid haemorrhage. Ann Neurol 1999;27:106-108.

12. Diringer MN, Wu KC, Verbalis JG, Hanley DF. Hypervolemic therapy prevents volume contraction but not hyponatremia following subarachnoid hemorrhage. Ann Neurol 1992;31:543-550.

13. Peters JP, Welt LG, Sims EA, Orloff J, Needham J. A salt-wasting syndrome associated with cerebral disease. Trans Assoc Am Physicians 1950;63:57-64.

14. Schwartz WB, Bennett W, Curelop S, Bartter FC. A syndrome of renal sodium loss and hyponatremia probably resulting from inappropriate secretion of antidiuretic hormone. Am J Med 1957;23:529-542.
15. Bartter FC, Schwartz WB. The syndrome of inappropriate secretion of antidiuretic hormone. Am J Med 1967;42:790-806.

16. Vingerhoets F, Tribolet N. Hyponatremia hypo-osmolarity in neurosurgical patients: "appropriate secretion of $\mathrm{ADH}^{\circ}$ and "cerebral salt wasting syndrome“. Acta Neurochir 1988;91:50-54.

17. Yamaki T, Tano-Oka A, Takahashi A, Imaizumi T, Suetake K, Hashi K. Cerebral salt wasting distinct from syndrome of inappropriate secretion of antidiuretic hormone (SIADH). Acta Neurochir 1992;115:156-162.

18. Wijdicks EF, Vermeulen M, Hijdra A, van Gijn J. Hyponatremia and cerebral infarction in patients with ruptured intracranial aneurysms. Is fluid restriction harmful? Ann Neurol 1985;17:137-140.

19. Coenraad MJ, Meinders AE, Taal JC, Bolk JH. Hyponatremia in intracranial disorders. Netherlands J Med 2001;58:123-127.

20. Chung HM, Kluge R, Schrier RW, Anderson RJ. Postoperative hyponatremia: a prospective study. Arch Intern Med 1986;146:333-336.

21. Robertson GL, Mahr EA, Athar S, Sinha T. Development and clinical application of a new method for radioimmunoassay of arginine vasopressin in human plasma. J Clin Invest 1973;52:2340-2352.

22. Saborio P, Tipton GA, Chan JC. Diabetes insipidus. Pediatr Rev 2000;21: 122-129.

23. Reeder RF, Harbaugh RE. Administration of intravenous urea and normal saline for the treatment of hyponatremia in neurosurgical patients. J Neurosurg 1989;70:201-206.

24. Rabinstein AA, Wijdicks EF. Hyponatremia in critically ill neurological patients: review. Neurologist 2003;9:290-300.

25. Miller M. Syndrome of excess antidiuretic hormone release. Crit Care Clin 2001;17:11-23.

26. Dickerson RN. Hyponatremia in neurosurgical patients: syndrome of inappropriate antidiuretic hormone or cerebral salt wasting syndrome? Hospital Pharmacy 2002;12:1336-1340.

27. Oh MS, Carroll HJ. Cerebral salt wasting syndrome: we need better proof of its existence. Nephron 1999;82:110-114.

28. Isotani E, Suzuki R, Tomita K, et al. Alterations in plasma concentrations of natriuretic peptides and antidiuretic hormone after subarachnoid hemorrhage. Stroke 1994;25:2198-2203.

29. Laredo S, Yuen K, Sonnenberg B, Halperin ML. Coexistence of central diabetes insipidus and salt wasting: the difficulties in diagnosis, changes in natremia and treatment. J Am Soc Nephrol 1996;7:2527-2532.

30. Tisdall M, Crocker M, Watkiss J, Smith FRCA. Disturbances of sodium in critically ill adult neurologic patients: clinical review. J Neurosurg Anestesiol 2006;18:57-63. 